\title{
Three-dimensional changes in the upper airway and craniomaxillofacial morphology of patients with Angle Class III malocclusion treated with a Frankel III appliance
}

Yinan Liu and Kai Yang*

\begin{abstract}
Background: Angle Class III malocclusion, characterized by a concave profile, can cause serious harm to children's physical and mental health. The Frankel III appliance is an effective treatment for Angle Class III malocclusion in mixed denition. We explored three-dimensional changes in the upper airway and craniomaxillofacial morphology, after one year of Frankel III appliance treatment, in children with Angle Class III malocclusion.
\end{abstract}

Methods: We included 20 children (9 males), aged 8-10 years, with Angle Class III malocclusion from the Orthodontics Department of our hospital. Each child was treated with a Frankel III appliance for one year. Cone beam computed tomography was performed before and after treatment to evaluate three-dimensional changes in the upper airway and craniomaxillofacial morphology.

Results: After one year of treatment, in the upper airway, we observed significant increases in the nasopharynx volume and height $(P<0.05)$; the velopharyngeal volume, height, and average cross-sectional area $(P<0.05)$; the glossopharynx volume and minimum cross-sectional area $(P<0.05)$; and the laryngopharynx height $(P<0.05)$. Accordingly, the total upper airway volume, height, and average cross sectional area increased significantly $(P<0.05)$. An examination of craniomaxillofacial morphology showed significant increases in some bone tissues $(P<0.05)$ and dental measurements, and a significant reduction in the inclination of the mandibular central incisor $(P<0.05)$.

Conclusion: Children with Angle class III malocclusion treated with a Frankel III appliance showed no upper airway narrowing, even after repositioning the mandible posteriorly. Moreover, treatment promoted forward maxilla development and increased its width, in both the dental arch and alveolar bone, which provided a more harmonious craniofacial morphology.

Keywords: Frankel III appliance, Upper airway, Craniomaxillofacial morphology

*Correspondence: dr_yangkai@163.com; yangkai_cn@hotmail.com Department of Orthodontics, Beijing Stomatological Hospital, Capital Medical University, Tian Tan Xi Li \#4, Dongcheng District, Beijing 100050, China

\section{Background}

Angle Class III malocclusion has long been considered a complicated maxillofacial disorder characterized by a concave profile, which may include mandibular protrusion, maxillary retrusion, or a combination of the two [1]. If the symptoms worsen with patient growth, the condition might require orthognathic surgery in adulthood. 
Thus, orthodontists should place more emphasis on the early treatment of Angle Class III malocclusion.

The Frankel III appliance is an effective treatment for Angle Class III malocclusion that is currently implemented worldwide [2]. Before applying the Frankel III appliance, the mandible was gently guided posteriorly, to the centric position, for wax bite construction [3]. The Frankel III appliance treatment led to an occlusal plane rotation that shifted the molar configuration from a Class III to a Class I angle [4].

Some studies have reported that treatments with a Frankel III appliance had clear effects on maxillary development [5], dentoalveolar development, skeletal widths [6], and the shape and position of the mandible and maxilla [5]. However, they mentioned that analyses based on two-dimensional cephalometric measurements as the sole indicators had some shortcomings, which may have affected the results. Moreover, upper airway is closely related to the craniomaxillofacial structure [7, 8]. But to the best of our knowledge, no previous studies have described changes in pharyngeal size after treating Angle class III malocclusions with Frankel III appliance in children that are growing and developing.

Therefore, the objective of study is to explore the threedimensional changes in the upper airway and craniomaxillofacial morphology after treatment with a Frankel III appliance using the cone beam computed tomography $(\mathrm{CBCT})$.

\section{Materials and method}

\section{Study design and sample}

This study included 20 children (9 males and 11 females), 8 to 10 years old, in a stage of mixed dentition. Patients were recruited from the Orthodontics Department of our hospital. The selection criteria were Angle Class III malocclusion; $\mathrm{ANB}<0^{\circ}$; an anterior crossbite, where the edge-to-edge incisor relationship was in a retruded contact position; good cooperation during the treatment period; the patient had undergone one year of orthodontic treatment with a Frankel III appliance; CBCTs were taken before and after treatment, and image areas were complete and clear, without movement artifacts; and the images had to include clear views of the nasion point $(\mathrm{N})$, hyoid bone, epiglottis valley bottom, and other points of interest.

\section{Data collection}

All CBCT scans were performed by a specialist in radiology in the Radiology Department of our hospital. Under the unified mode, the CBCT equipment (NewTom VG; AFP; Verona, Italy) was set to the following parameters: 1-20 mA (pulsed mode), $110 \mathrm{kV}$ voltage, $3.6 \mathrm{~s}$ effective exposure time, $60 \mathrm{~s}$ reconstruction time, whole skull mode. During image acquisition, patients were instructed to bite down, in the intercuspal position. All CBCT images were exported in DICOM format (Digital Imaging and Communications in Medicine), and three-dimensional images of the craniomaxillofacial morphology, upper airway, and hyoid were reconstructed with Dolphin Imaging software (version 11.8; Dolphin Imaging \& Management Solutions, Chatsworth, CA).

\section{Data analysis}

Before taking any measurements, the three-dimensional coordinate system was established. The orientation function provided in the software was applied to adjust the head position and orient the planes in the threedimensional coordinate system (Fig. 1). Referring to the methods of Shin et al. [9], Yang et al. [7], and the threedimensional coordinate axis instructions provided in the software, we established the nasion point as the origin in the three-dimensional coordinate system.

First, we set the Frankfort horizontal plane, which was aligned with the top point of the external auditory canal and the lowest point of the infraorbital edge. When the bilateral orbitales and porions were not located on the same plane, we set the Frankfort horizontal plane between them, at the minimum squared distance from all four points. Then, we determined the midsagittal plane, which was aligned with the nasion point, the anterior nasal spine (ANS) point, and the basion point. The $\mathrm{X}$-axis was defined as the line parallel to the Frankfort horizontal plane that passed through the nasion point. The $\mathrm{Z}$-axis was defined as the line perpendicular to the $\mathrm{X}$-axis

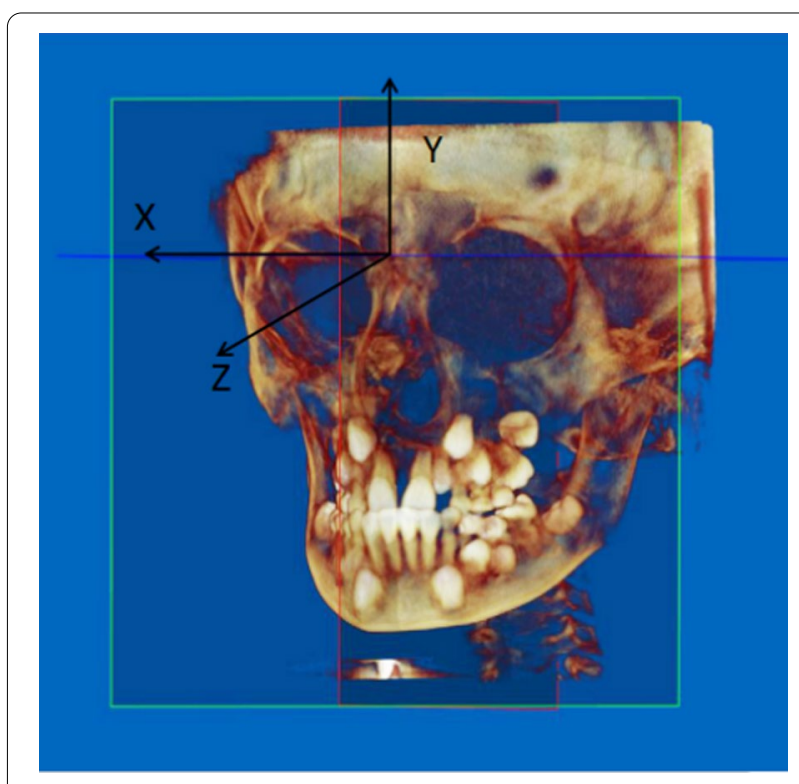

Fig. 1 Determination of the three-dimensional coordinate system 
that passed through the nasion point on the midsagittal plane. The Y-axis was defined as the line perpendicular to the $\mathrm{Z}$ - and $\mathrm{X}$-axes that passed through the nasion point. Therefore, any point in this space was automatically fixed in three-dimensional coordinate values $(x, y, z)$ with the software (Fig. 2). The craniomaxillofacial morphology assessment was based on 25 landmarks (Table 1), each measured on the X-, Y-, and Z-axes.

The upper airway sections were based on the anatomical divisions described by Yang et al. [7], and Shin et al. [9]. In this study, the nasopharynx area was located between the top of the upper airway and the horizontal plane that passed through the posterior nasal spine. The velopharynx area was located between the end of the nasopharynx and the horizontal plane that passed through the end of the soft palate. The glossopharynx area was between the end of the velopharynx and the horizontal plane that passed through the top of the epiglottis. Finally, the laryngopharynx area was between the end of the glossopharynx and the horizontal plane that passed through the epiglottis vallecula (Fig. 3). The total upper airway area was defined as sum of these four sections. The software could automatically calculate the airway volume, find the minimum cross-section, and calculate the minimum cross-sectional area (Fig. 4). To evaluate the three-dimensional changes in the upper airway, we measured the volumes, heights, and diameters. Additionally, we calculated the average cross-sectional areas of the four pharyngeal cavities (Table 2).
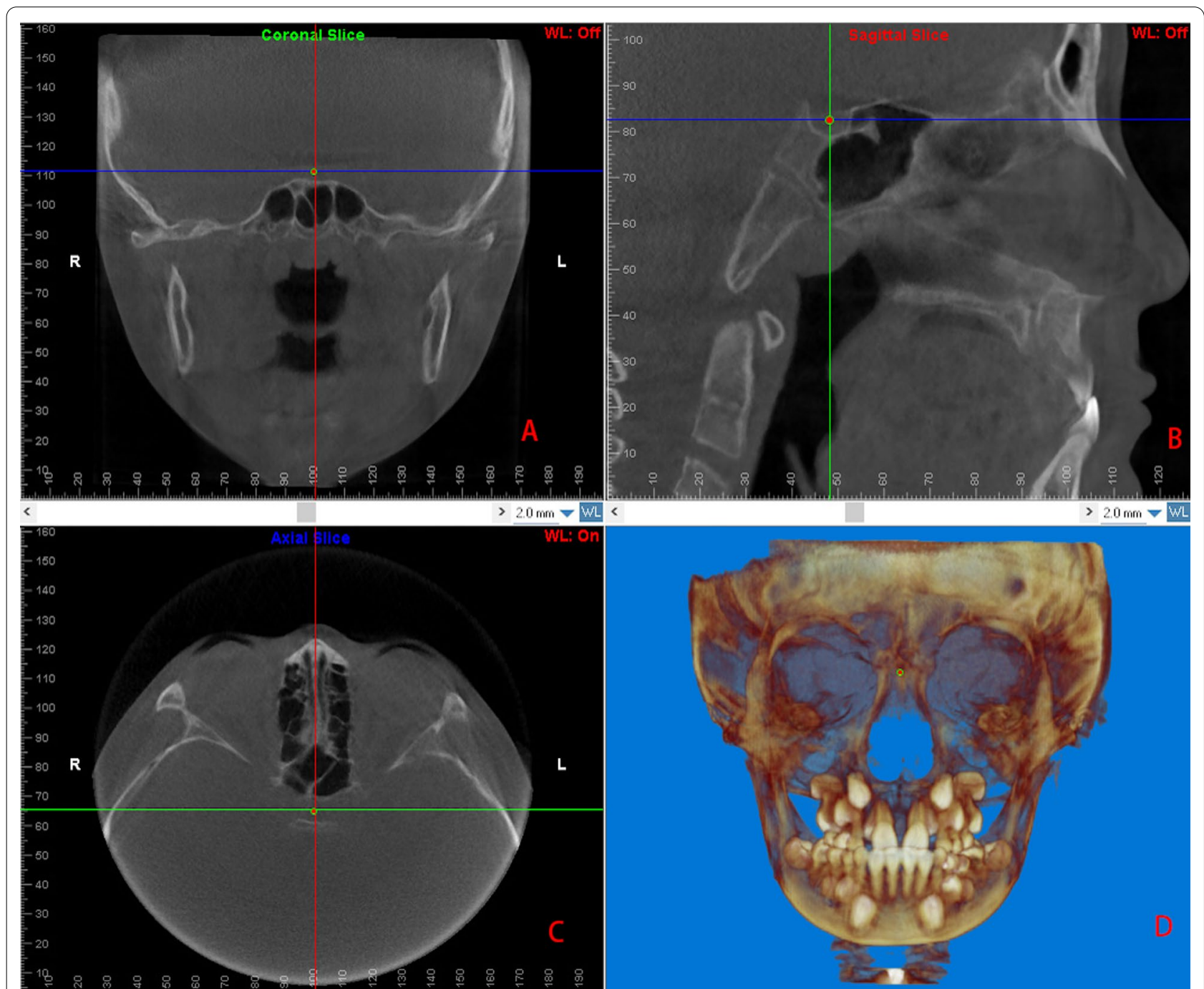

Fig. 2 Three-dimensional fixed points. This figure shows the sella point on the coronal plane (A), sagittal plane (B), horizontal plane (C), and its overall view (D) 
Table 1 Items measured to assess craniomaxillofacial morphology

\begin{tabular}{|c|c|}
\hline Items & Definition \\
\hline SNA & The angle formed by lines between the sella, nasion, and subspinale points, which represents the sagittal position of the maxilla \\
\hline SNB & The angle formed by lines between the sella, nasion, and supramental points, which represents the sagittal position of the mandible \\
\hline ANB & $\begin{array}{l}\text { The angle formed by lines between the subspinale, nasion, and supramental points, which represents the sagittal position of the } \\
\text { maxilla and mandible }\end{array}$ \\
\hline S-N & The distance between the sella and nasion points, which indicates the length of the anterior basis cranii \\
\hline S-Ba & The distance between the sella and basion points, which indicates the length of posterior basis cranii \\
\hline ZyR-ZyL & The distance between the bilateral zygomatic arch which indicates the width of the hard tissue surface \\
\hline $\mathrm{N}-\mathrm{Me}$ & The distance between the nasion and menton points, which indicates the overall height of the hard tissue \\
\hline ANS-Me & The distance between the anterior nasal spine (ANS) and the menton point, which indicates the height of the lower hard tissue \\
\hline ANS-Me/N-Me & The ratio of the ANS-Me to the N-Me \\
\hline PNS-ANS & The distance between the anterior nasal spine (ANS) and the posterior nasal spine (PNS) \\
\hline$J-J$ & $\begin{array}{l}\text { The distance between the bilateral jugal points (the most concave point between the maxillary tubercle and the zygomatic process), } \\
\text { which indicates the width of the maxilla }\end{array}$ \\
\hline GoR-GoL & The distance between the bilateral gonion points, which indicates the width of the mandible \\
\hline Co-Go & The distance between the condylion and gonion points, which indicates the length of the ramus of the mandible \\
\hline Go-Me & The distance between the gonion and menton points, which indicates the length of the mandible \\
\hline Co-Go-Me & The angle formed by lines between the condylion, gonion, and menton points, which indicates the angle of the mandible \\
\hline MP-FH & $\begin{array}{l}\text { The angle between the plane of mandible inclination (MP) and the Frankfort horizontal (FH) plane, which indicates the angle of the } \\
\text { mandible }\end{array}$ \\
\hline U1-SN & $\begin{array}{l}\text { The angle between the long axis of the upper incisor (U1) and the sella-nasion (SN) plane of the maxillary central incisor, which indi- } \\
\text { cates the inclination of the maxillary central incisor }\end{array}$ \\
\hline L1-MP & The angle between the long axis (L1) of the mandible central incisor and its plane of inclination (MP) \\
\hline U1-L1 & The angle of upper incisor to lower incisor \\
\hline $\begin{array}{l}\text { MBBW (maxil- } \\
\text { lary buccal } \\
\text { basal bone } \\
\text { width) }\end{array}$ & The horizontal distance between the most concave points of the buccal basal bone, near the root tip, on the coronal plane \\
\hline $\begin{array}{l}\text { MFMW (maxil- } \\
\text { lary first molar } \\
\text { width) }\end{array}$ & $\begin{array}{l}\text { The horizontal distance between the central fossa of the first molar on both sides of the maxilla, which indicates the width of the } \\
\text { posterior arch }\end{array}$ \\
\hline $\mathrm{H}-\mathrm{CVP}$ & $\begin{array}{l}\text { The distance between the topmost point of the hyoid body }(\mathrm{H}) \text { and a line placed tangent to the anterior surfaces of the bodies of the } \\
\text { second, third, and fourth cervical vertebrae }\end{array}$ \\
\hline H-MP & The distance between the uppermost point of the hyoid body and the MP \\
\hline $\mathrm{H}-\mathrm{FH}$ & The distance between the topmost point of the hyoid body and the Frankfort plane \\
\hline PNS-CVP & $\begin{array}{l}\text { The distance between the posterior nasal spine (PNS) and a line placed tangent to the anterior surfaces of the bodies of the second, } \\
\text { third, and fourth cervical vertebrae }\end{array}$ \\
\hline Me-CVP & $\begin{array}{l}\text { The distance between the menton and a line placed tangent to the anterior surfaces of the bodies of the second, third, and fourth } \\
\text { cervical vertebrae }\end{array}$ \\
\hline
\end{tabular}

\section{Statistical analysis}

To reduce the errors, all the values were measured three times by an orthodontic student with professional training, and the average values were analyzed. We performed statistical analyses with SPSS software (version 22.0; IBM, Armonk, NY). We performed the Wilcoxon signed rank test to evaluate differences between measurements taken before and after treatment.

\section{Results}

This prospective study included 20 patients, aged 8-10 years. The three-dimensional changes observed in the upper airway are shown in Table 3. After one year of treatment with the Frankel III appliance, we observed significant increases in the height and volume of the nasopharynx $(P<0.05)$; the height, volume, and the average cross-sectional area of the velopharynx $(P<0.05)$; the 


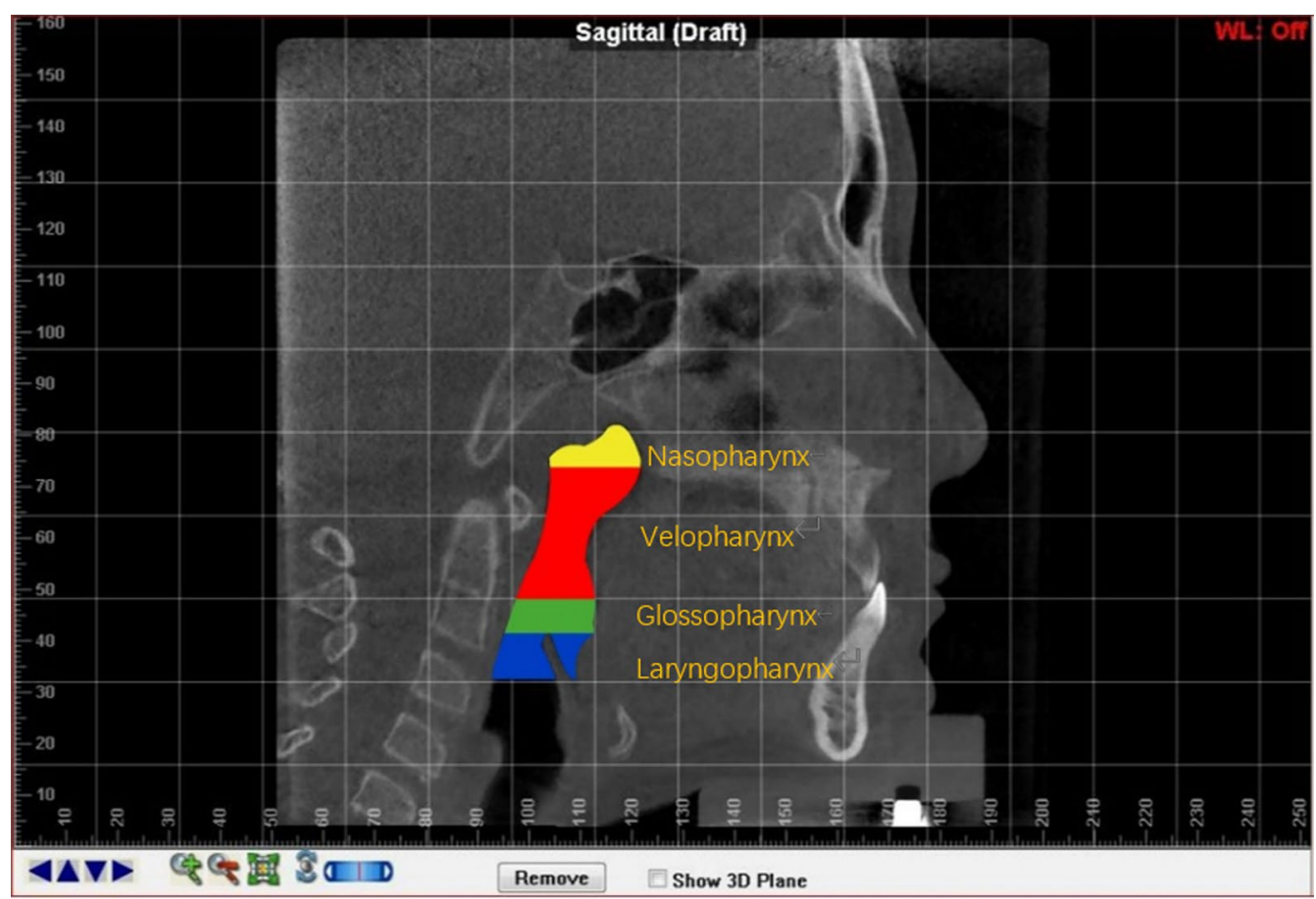

Fig. 3 Sagittal view of the upper airway anatomical subsections
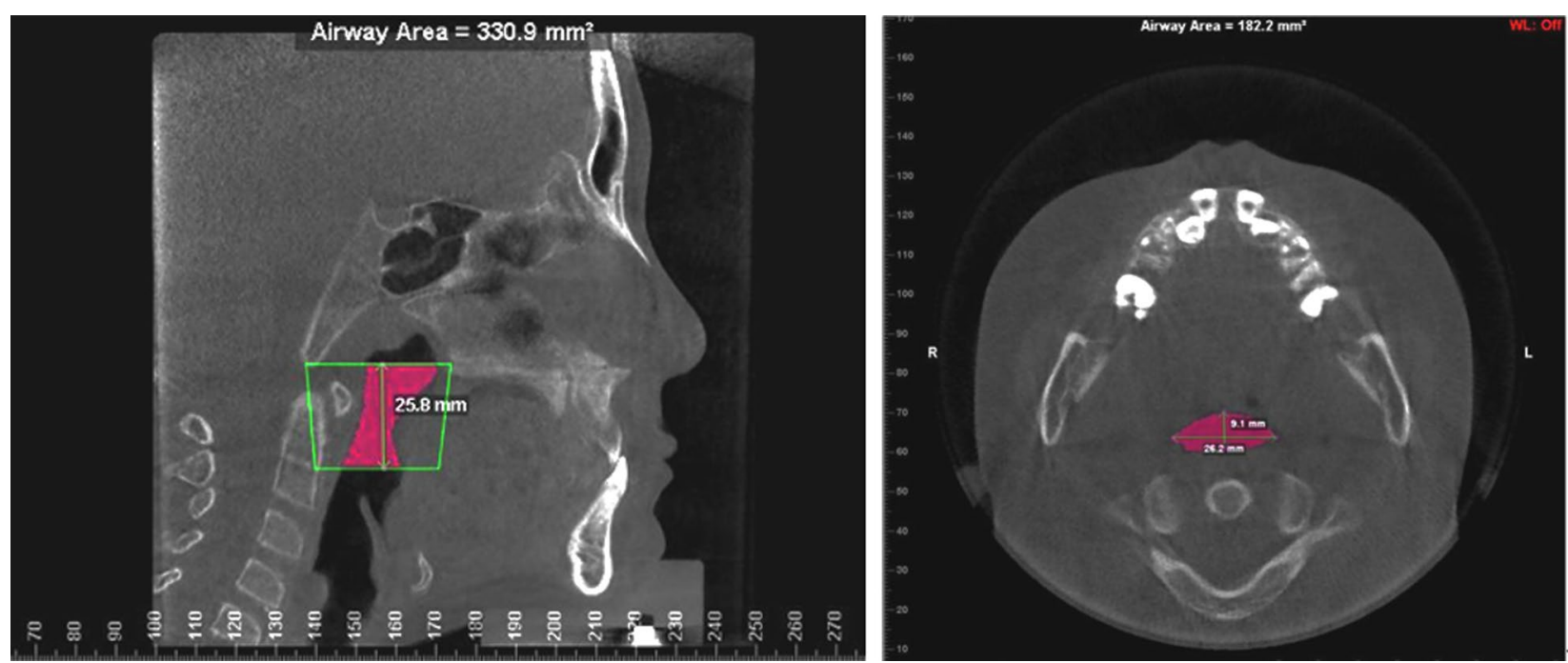

Fig. 4 Calculate the upper airway items. The volume is calculated as (left) the height of the pharyngeal cavity, multiplied by (right) the minimum cross-sectional area, which is automatically

volume and minimum cross-sectional area of the glossopharynx $(P<0.05)$; and the height of the laryngopharynx $(P<0.05)$. Accordingly, we observed significant increases in the volume, height, and average cross-sectional area of the total upper airway $(P<0.05)$. The other items in the upper airway increased, but not significantly
$(P>0.05)$, except for the anteroposterior velopharyngeal diameter, which remained nearly constant. Overall, no measurement was significantly reduced in the upper airway.

The changes in craniomaxillofacial morphology are presented in Table 4. After one year of treatment with 
Table 2 Items measured to assess the upper airway

\begin{tabular}{|c|c|}
\hline Items & Definition \\
\hline Nasopharyngeal volume (Na-V) & Nasopharynx volume, calculated by simulation \\
\hline Nasopharyngeal height (Na-H) & The linear distance between the upper and lower boundaries of the nasopharynx \\
\hline Nasopharyngeal average cross-sectional area (Na-CSAavg) & Ratio of the nasopharyngeal volume to its height \\
\hline Velopharyngeal volume (Ve-V) & Velopharyngeal volume, calculated by simulation \\
\hline Minimum velopharyngeal cross-sectional area (Ve-CSAmin) & $\begin{array}{l}\text { The minimum cross-sectional area of the palatopharyngeal segment, identified and } \\
\text { calculated automatically }\end{array}$ \\
\hline Anteroposterior velopharyngeal diameter (Ve-AP) & $\begin{array}{l}\text { Anterior-posterior distance at the minimum cross-section of the velopharyngeal seg- } \\
\text { ment }\end{array}$ \\
\hline Lateral velopharyngeal diameter (Ve-LAT) & Lateral-medial distance at the minimum cross-section of the velopharyngeal segment \\
\hline Velopharyngeal height (Ve-H) & Distance between the upper and lower boundaries of the velopharyngeal segment \\
\hline Velopharyngeal average cross-sectional area (Ve-CSAavg) & Ratio of the velopharyngeal volume to its height \\
\hline Glossopharyngeal volume (GI-V) & Glossopharyngeal volume, calculated automatically by the system \\
\hline Glossopharyngeal minimum cross-sectional area (GI-CSAmin) & $\begin{array}{l}\text { The minimum cross-sectional area of the glossopharyngeal segment, identified and } \\
\text { calculated automatically }\end{array}$ \\
\hline Anteroposterior glossopharyngeal diameter (GI-AP) & $\begin{array}{l}\text { Anterior-posterior distance at the minimum cross-section of glossopharyngeal seg- } \\
\text { ment }\end{array}$ \\
\hline Lateral glossopharyngeal diameter (GI-LAT) & Lateral-medial distance at the minimum cross-section of glossopharyngeal segment \\
\hline Glossopharyngeal height (GI-H) & $\begin{array}{l}\text { The linear distance between the upper and lower boundaries of the glossopharyngeal } \\
\text { segment }\end{array}$ \\
\hline Laryngopharynx volume (La-V) & Laryngopharynx volume, calculated by simulation \\
\hline Minimum laryngopharynx cross-sectional area (La-CSAmin) & $\begin{array}{l}\text { The minimum cross-sectional area of the laryngopharynx segment, identified and } \\
\text { calculated automatically }\end{array}$ \\
\hline Anteroposterior laryngopharynx diameter (La-AP) & $\begin{array}{l}\text { Anterior-posterior distance at the minimum cross-section of the laryngopharyngeal } \\
\text { segment }\end{array}$ \\
\hline Lateral laryngopharynx diameter (La-LAT) & $\begin{array}{l}\text { Lateral-medial distance at the minimum cross-section of the laryngopharyngeal seg- } \\
\text { ment }\end{array}$ \\
\hline Laryngopharynx height (La-H) & $\begin{array}{l}\text { The linear distance between the upper and lower boundaries of the laryngopharyngeal } \\
\text { segment }\end{array}$ \\
\hline Laryngopharynx average cross-sectional area (La-CSAavg) & Ratio of the laryngopharynx volume to its height \\
\hline Total volume of the upper airway (T-V) & Sum of the volumes of the upper airway segments \\
\hline Total height of the upper airway $(\mathrm{T}-\mathrm{H})$ & Sum of the heights of the upper airway segments \\
\hline Average cross-sectional area of the upper airway (T-CSAavg) & Ratio of the total volume of the upper airway to its total height \\
\hline
\end{tabular}

the Frankel III appliance, we observed large changes in craniomaxillofacial morphology. In the sagittal direction, SNA and ANB increased significantly $(P<0.05)$, which indicated that the Frankel III appliance promoted the development of the maxilla and adjusted the relationship between the two jaws. We also observed significant changes in the sella-nasion (S-N) and sella-basion ( $\mathrm{S}-\mathrm{Ba})$ distances $(P<0.05)$. We observed significant increases in the distance between the nasion and menton points (N-Me), the distance between the ANS and the menton (ANS-Me), and the ratio of the ANS-Me to the N-Me $(P<0.05)$, which indicated an increase in the anterior face height, particularly in the anterior lower face. We also observed an increase in the distance between the anterior and posterior nasal spines (PNS-ANS) $(P<0.05)$, which indicated that the presenting length of the maxilla increased. The distance between the condylion and gonion points (Co-Go) increased, which indicated an increase in the length of the ramus of the mandible $(P<0.05)$. We also observed significant increases in the distance between the gonion and menton points (Go$\mathrm{Me}$ ) and the distance between the menton point and the cervical vertebrae plane (Me-CVP), which indicated an increase in the length of the mandible $(P<0.05)$. The significant increases observed in the distance between the topmost point of the hyoid body and the cervical vertebrae plane (H-CVP) and the distance between the topmost point of the hyoid body and the Frankfort plane $(\mathrm{H}-\mathrm{FH})$ indicated that the hyoid bone had moved forward and downward $(P<0.05)$ with treatment. The inclination of the maxillary central incisor (U1-SN) increased significantly, and the angle between the long axis of the mandible central incisor and its plane of inclination (L1-MP) decreased significantly $(P<0.05)$. These findings indicated that the upper anterior teeth had inclined labially, and the lower anterior teeth had inclined lingually. 
Table 3 Three-dimensional measurements in the upper airway before and after treatment

\begin{tabular}{|c|c|c|c|c|}
\hline Section & Items $^{a}$ & Before & After & $P$ \\
\hline \multirow[t]{3}{*}{ Nasopharynx } & $\mathrm{Na}-\mathrm{V}\left(\mathrm{mm}^{3}\right)$ & $3701.09 \pm 1292.52$ & $4543.21 \pm 1414.34$ & $0.003^{* *}$ \\
\hline & $\mathrm{Na}-\mathrm{H}(\mathrm{mm})$ & $11.05 \pm 1.91$ & $12.34 \pm 2.45$ & $0.001^{* *}$ \\
\hline & $\mathrm{Na}$-CSAavg $\left(\mathrm{mm}^{2}\right)$ & $343.05 \pm 135.25$ & $375.72 \pm 128.38$ & 0.079 \\
\hline \multirow[t]{6}{*}{ Velopharynx } & $V e-V\left(m^{3}\right)$ & $6209.95 \pm 2578.33$ & $7735.10 \pm 3173.06$ & $0.009^{* *}$ \\
\hline & Ve-CSAmin $\left(\mathrm{mm}^{2}\right)$ & $131.21 \pm 78.71$ & $166.99 \pm 105.15$ & 0.067 \\
\hline & Ve-AP (mm) & $12.08 \pm 3.15$ & $12.02 \pm 3.54$ & 0.970 \\
\hline & Ve-LAT (mm) & $18.58 \pm 6.86$ & $20.54 \pm 7.01$ & 0.232 \\
\hline & $\mathrm{Ve}-\mathrm{H}(\mathrm{mm})$ & $24.74 \pm 2.80$ & $26.26 \pm 3.48$ & $0.004^{* *}$ \\
\hline & Ve-CSAavg (mm) & $253.41 \pm 104.99$ & $295.58 \pm 115.92$ & $0.017^{*}$ \\
\hline \multirow[t]{6}{*}{ Glossopharynx } & $\mathrm{Gl}-\mathrm{V}\left(\mathrm{mm}^{3}\right)$ & $2831.44 \pm 1449.25$ & $3859.90 \pm 2248.44$ & $0.021^{*}$ \\
\hline & Gl-CSAmin $\left(\mathrm{mm}^{2}\right)$ & $139.56 \pm 65.01$ & $177.12 \pm 75.66$ & $0.025^{*}$ \\
\hline & $\mathrm{Gl}-\mathrm{AP}(\mathrm{mm})$ & $11.43 \pm 2.82$ & $12.42 \pm 2.76$ & 0.185 \\
\hline & Gl-LAT (mm) & $21.71 \pm 7.50$ & $23.341 \pm 7.75$ & 0.467 \\
\hline & $\mathrm{Gl}-\mathrm{H}(\mathrm{mm})$ & $13.17 \pm 3.85$ & $14.52 \pm 3.95$ & 0.370 \\
\hline & Gl-CSAavg $\left(\mathrm{mm}^{2}\right)$ & $217.84 \pm 85.48$ & $260.49 \pm 113.70$ & 0.086 \\
\hline \multirow[t]{6}{*}{ Laryngopharynx } & $\mathrm{La}-\mathrm{V}\left(\mathrm{mm}^{3}\right)$ & $2485.25 \pm 995.76$ & $3283.71 \pm 2120.79$ & 0.057 \\
\hline & La-CSAmin $\left(\mathrm{mm}^{2}\right)$ & $156.05 \pm 74.19$ & $176.49 \pm 85.46$ & 0.526 \\
\hline & La-AP (mm) & $9.94 \pm 3.07$ & $11.01 \pm 3.56$ & 0.263 \\
\hline & La-LAT (mm) & $28.47 \pm 3.24$ & $29.37 \pm 4.89$ & 0.191 \\
\hline & $\mathrm{La}-\mathrm{H}(\mathrm{mm})$ & $9.40 \pm 1.58$ & $10.39 \pm 2.27$ & $0.017^{*}$ \\
\hline & La-CSAavg $\left(\mathrm{mm}^{2}\right)$ & $259.84 \pm 82.35$ & $302.68 \pm 132.98$ & 0.135 \\
\hline \multirow[t]{3}{*}{ Total upper airway } & $\mathrm{T}-\mathrm{V}\left(\mathrm{mm}^{3}\right)$ & $15,227.72 \pm 5235.83$ & $19,421.92 \pm 7102.11$ & $0.005^{* *}$ \\
\hline & $\mathrm{T}-\mathrm{H}(\mathrm{mm})$ & $58.356 \pm 5.37$ & $63.51 \pm 6.88$ & $0.000^{* *}$ \\
\hline & T-CSAavg $\left(\mathrm{mm}^{2}\right)$ & $262.25 \pm 87.59$ & $303.64 \pm 95.74$ & $0.025^{*}$ \\
\hline
\end{tabular}

**P $P<0.01,{ }^{*} P<0.05$

${ }^{\text {a }}$ See Table 2 for definitions of these abbreviations

The distance between the bilateral jugal points (J-J) and the distance between the bilateral gonion points (GoRGoL) increased with treatment, which indicated that the widths of the maxilla and mandible increased significantly $(P<0.05)$. We also observed significant increases in the maxillary first molar width (MFMW) and the maxillary buccal basal bone width $(\mathrm{MBBW})(P<0.05)$, which indicated that the widths of the maxilla arch and base bone had increased with treatment.

\section{Discussion}

In this study, SNA angle significantly increased, by $1.74^{\circ}$, after one year of treatment. This finding verified the effects of Frankel III appliance treatment on the maxilla. Besides, the maxilla widths in both the dental and alveolar areas increased significantly. These increases may have been caused by the vestibular shields of the Frankel III device, which eliminated the restrictive pressure of the buccinator on the maxilla bone and dental arch. Additionally, we observed a significant change in the length of the ramus of the mandible and the distance between the menton and the cervical vertebrae. This finding indicated that the growth of mandible was not inhibited. Overall, the total volume, height, and average cross-sectional area of the upper airway increased significantly. Thus, the total upper airway was larger after treatment than before treatment with the Frankel III appliance.

The nasopharynx is one of the most important areas of the upper airway, due to its close relationship to the occurrence of obstructive sleep apnea hypopnea syndrome [10]. Brodie and King stated that the total depth of the nasopharynx is established in the first or second years of life [11, 12]. King also showed that, with growth, increases in the depth of the nasopharynx at the sphenooccipital junction are minimized by the forward growth of the anterior arch of the atlas. Furthermore, there is a positive correlation between the cranial base and the nasopharyngeal depth; thus, the more obtuse the base, the greater the depth, as mentioned by Ricketts and Bergland $[10,11]$. In contrast to the early establishment of the nasopharyngeal depth, King demonstrated that the nasopharyngeal height continued to increase until maturity [12]. He accounted for this increase by the descent of the hard palate and cervical vertebrae from the cranium. 
Table 4 Three-dimensional measurements of craniomaxillofacial morphology before and after treatment

\begin{tabular}{|c|c|c|c|}
\hline Measurement items $\mathrm{s}^{\mathrm{a}}$ & Before & After & $P$ \\
\hline SNA $\left(^{\circ}\right)$ & $79.73 \pm 2.74$ & $81.47 \pm 2.94$ & $0.001^{* *}$ \\
\hline SNB $\left(^{\circ}\right)$ & $80.15 \pm 2.93$ & $79.40 \pm 3.42$ & 0.076 \\
\hline ANB $\left(^{\circ}\right)$ & $-0.42 \pm 2.57$ & $2.07 \pm 1.94$ & $0.000^{* *}$ \\
\hline $\mathrm{S}-\mathrm{N}(\mathrm{mm})$ & $59.27 \pm 3.05$ & $60.62 \pm 3.58$ & $0.000^{* *}$ \\
\hline $\mathrm{S}-\mathrm{Ba}(\mathrm{mm})$ & $41.55 \pm 2.10$ & $43.14 \pm 3.16$ & $0.000^{* *}$ \\
\hline ZyR-ZyL (mm) & $109.11 \pm 3.23$ & $111.18 \pm 3.19$ & $0.004^{* *}$ \\
\hline $\mathrm{N}-\mathrm{Me}(\mathrm{mm})$ & $101.74 \pm 11.70$ & $109.44 \pm 6.24$ & $0.000^{* *}$ \\
\hline ANS-Me (mm) & $57.47 \pm 3.17$ & $62.05 \pm 3.89$ & $0.000^{* *}$ \\
\hline ANS-Me/N-Me (\%) & $48.77 \pm 2.29$ & $50.31 \pm 2.17$ & $0.019^{*}$ \\
\hline PNS-ANS (mm) & $42.80 \pm 3.92$ & $45.27 \pm 4.26$ & $0.001^{* *}$ \\
\hline$J-J(m m)$ & $67.49 \pm 2.47$ & $70.63 \pm 4.06$ & $0.000^{* *}$ \\
\hline GoR-GoL (mm) & $82.52 \pm 3.25$ & $84.48 \pm 4.27$ & $0.003^{* *}$ \\
\hline Co-Go (mm) & $52.24 \pm 4.75$ & $55.65 \pm 4.21$ & $0.003^{* *}$ \\
\hline Go-Me (mm) & $69.79 \pm 5.49$ & $73.14 \pm 6.07$ & $0.021^{*}$ \\
\hline Co-Go-Me (mm) & $126.55 \pm 5.68$ & $125.29 \pm 6.04$ & 0.370 \\
\hline $\mathrm{MP}-\mathrm{FH}(\mathrm{mm})$ & $33.38 \pm 5.26$ & $34.60 \pm 5.18$ & 0.232 \\
\hline U1-SN $\left(^{\circ}\right)$ & $102.11 \pm 7.98$ & $107.24 \pm 4.62$ & $0.007^{* *}$ \\
\hline $\operatorname{L1}-\mathrm{MP}\left(^{\circ}\right)$ & $108.74 \pm 17.51$ & $105.21 \pm 17.15$ & $0.005^{* *}$ \\
\hline U1-L1 $\left(^{\circ}\right)$ & $131.15 \pm 8.71$ & $130.60 \pm 6.56$ & 0.723 \\
\hline $\mathrm{MBBW}(\mathrm{mm})$ & $63.42 \pm 2.36$ & $64.87 \pm 2.22$ & $0.001^{* *}$ \\
\hline MFMW (mm) & $48.81 \pm 2.38$ & $50.70 \pm 2.68$ & $0.000^{* *}$ \\
\hline $\mathrm{H}-\mathrm{CVP}(\mathrm{mm})$ & $28.035 \pm 3.00$ & $30.48 \pm 4.76$ & $0.008^{* *}$ \\
\hline $\mathrm{H}-\mathrm{MP}(\mathrm{mm})$ & $24.34 \pm 3.49$ & $25.06 \pm 3.87$ & 0.239 \\
\hline $\mathrm{H}-\mathrm{FH}(\mathrm{mm})$ & $82.79 \pm 5.21$ & $87.28 \pm 7.59$ & $0.001^{* *}$ \\
\hline PNS-CVP (mm) & $22.40 \pm 4.60$ & $22.17 \pm 4.38$ & 0.550 \\
\hline $\mathrm{Me}-\mathrm{CVP}(\mathrm{mm})$ & $64.13 \pm 6.44$ & $67.72 \pm 8.57$ & $0.040^{*}$ \\
\hline
\end{tabular}

**P $<0.01,{ }^{*} P<0.05$

a See Table 1 for definitions of these abbreviations

Bergland found that nasopharyngeal height increased by $38 \%$ [13], from six years of age to maturity. Similarly, in our study, during the one year of treatment, the nasopharynx height increased by $11.67 \%$, and its volume increased by $22.75 \%$. However, the average cross-section of nasopharynx did not increase significantly, which may be due to the fact that the nasopharynx depth had been determined in early childhood.

It also has been reported that there was a countless relationship between the positions of the maxilla and nasopharynx $[14,15]$. Indeed, maxillary protraction significantly increased the dimensions of both the nasoand oro-pharyngeal airways. In our study, the distance between the posterior nasal spine and the cervical spine (PNS-CVP, Table 4) did not significantly change, which indicated that the distance from the back of the maxilla to the upper airway did not change. Consequently, there was no significant change in the depth of the nasopharynx. In other words, the Frankel III appliance increased the development of the anterior maxilla without changing the posterior maxilla.

The velopharynx is a muscular valve that extends from the posterior surface of the hard palate (roof of the mouth) to the posterior pharyngeal wall [16]. The velopharynx and surrounding oral and pharyngeal structures change rapidly during early development.

The velum and epiglottis separate at about 4 to 6 months of age [17], as the larynx moves from the level of the first cervical vertebra to the level of the third cervical vertebra. The rate of laryngeal descent is accelerated during the first 2 years of life, when the pharyngeal length increases by up to $2 \mathrm{~cm}$; this growth period is followed by more gradual lengthening [18]. This movement is accompanied by rapid growth of the pharynx, in the vertical dimension, from its newborn length, of about $4 \mathrm{~cm}$ to its adult length of approximately $12 \mathrm{~cm}$ [19]. In contrast, the anteroposterior dimension of the pharynx changes little from infancy to adulthood [12, 13, 18, 20, 21]. In our study, we observed clear increases in the height (6.14\%) and volume $(24.56 \%)$ of the velopharynx, during the one year of treatment. This finding indicated that increases in the velopharyngeal height and its average cross-sectional area (Ve-CSAavg) during this period led to a corresponding increase in its volume $(\mathrm{Ve}-\mathrm{V})$. However, the velopharyngeal anterior-posterior diameter (Ve-AP) remained almost unchanged, consistent with the above study, which showed that little change occurred in the anteroposterior dimension of velopharynx.

Few previous studies have investigated the development of the glossopharynx. As a part of oropharynx, the glossopharynx develops mainly in the vertical direction [22] and mainly due to increases in the height of the cervical vertebra. This process continues until adulthood, and two rapid growth periods are observed: one at 5-7 years old and the other at 12-15 years old. In our study, the glossopharynx height also increased, although not significantly. Previous studies also showed that the hyoid position could affect the size of the upper airway. Indeed, hyoid retrogression, caused by mandible retrogression, could cause narrowing of the upper airway [23]. In our study, although the mandible was guided backward for bite construction, SNB did not decrease significantly, due to growth. In contrast, the distances between the hyoid and the cervical vertebrae and between the hyoid and the Frankfort plane increased significantly. These findings indicated that the hyoid bone had moved forward and downward, which may have contributed to the profound increases in the minimum cross-sectional area and volume of the glossopharynx.

Lieberman et al. studied the growth and development of the laryngopharynx [24]. They found that the height of the laryngopharynx increased significantly from birth 
to 6-8 years old, and after that, it remained stable. King also found that, at the peak of growth and development, the depth of the laryngopharynx increased little, due to the forward movements of the hyoid and mandible [12]. In the present study, the height of the laryngopharynx increased significantly, by $10.53 \%$. Although the hyoid bone moved forward, the laryngopharynx showed increases in the minimum cross-sectional area (La-CSAmin) and the lateral and anterior-posterior diameters (La-LAT, La-AP), but the increases were not significant.

Progress of digitization in dental fields proposes a speed of treatment planning and a reliability of results [25]. The unique feature of our study was that we performed CBCT to measure three-dimensional changes in the upper airway and craniomaxillofacial morphology to obtain more comprehensive and accurate measurements. The American Dental Association recommended the following indications for $\mathrm{CBCT}$ in orthodontic treatments: observation of tooth development, limitation of tooth movement, airway evaluation, craniofacial morphology etc. [26]. CBCT has several advantages over 2D imaging, such as improved image quality, three-dimensional reconstructions, and a 1:1 ratio, which allowed accurate determination of reference points [27] and reliable measurements. Moreover, CBCT provided the ability to visualize craniofacial structures with a short exposure time and a lower radiation dose, compared to traditional computed tomography [28]. Once a CBCT is acquired, there is no need for lateral, frontal, and curvilinear cephalometric radiographs, due to the three-dimensional nature of the CBCT. In our study, the two CBCTs were performed one year apart; therefore, they caused almost no radiation damage to patients.

The main limitation of this study was the lack of a control group of children with Angle Class III malocclusion. A control group might have allowed us to rule out the influence of growth and developmental factors. However, it is not ethical to follow up this disorder without taking any action.

\section{Conclusions}

To summarize, the Frankel III appliance modified the growth and position of the mandible, which rotated backward and downward, and promoted maxillar development which produced a more harmonious relationship between the craniofacial bones. Furthermore, the upper airway did not narrow in response to this treatment.

\footnotetext{
Abbreviations

CBCT: Cone beam computed tomography; DICOM: Digital Imaging and Communications in Medicine; Ve-CSAavg: Velopharyngeal average cross-sectional
} area.
Acknowledgements

Not applicable.

\section{Authors' contributions}

YL contributed to this work and were involved in methodology, data collection, investigation, validation, software, data curation and writing —original draft preparation; $Y L$ and $\mathrm{KY}$ were involved in conceptualization; formal analysis and writing — review and editing; and KY were involved in conceptualization, supervision, project administration. Both authors read and approved the final manuscript.

\section{Funding}

This study was financially supported by Beijing Natural Science Foundation (7173260) and 'Beijing Hospitals Authority'Ascent Plan, Code: DFL20191501.

\section{Availability of data and materials}

The data analyzed this article will be shared on reasonable request to the corresponding author.

\section{Declarations}

\section{Ethical approval and consent to participate}

The study was performed analyzing patients using Frankel-III appliance of three-dimensional changes of upper airway and craniomaxillofacial morphology by CBCT. The study protocol was approved by the Ethics Review Board of our hospital, which was affiliated with the medical university (approval number: CMUSH-IRB-KJ-PJ-2017-07F). All procedures performed in this retrospective study involving human participants were in accordance with the ethical standards of the institutional and/or research.

\section{Consent for publication}

Patients signed informed consent regarding publishing their data and photographs. The authors understand that if the manuscript is accepted, the Editors reserve the right to determine whether it will be published in the print edition or solely in the Internet edition of the Journal. Articles accepted for publication are subject to editorial revision.

\section{Competing interests}

The authors declare that they have no competing interests.

Received: 4 November 2021 Accepted: 3 December 2021

Published online: 09 December 2021

\section{References}

1. Chang HP, Tseng YC, Chang HF. Treatment of mandibular prognathism. J Formos Med Assoc. 2006;105(10):781-90. https://doi.org/10.1016/S09296646(09)60264-3.

2. Fränkel R. Maxillary retrusion in Class 3 and treatment with the function corrector 3. 1970. p. 249-59

3. Baik HS, Jee SH, Lee KJ, Oh TK. Treatment effects of Fränkel functional regulator III in children with Class III malocclusions. Am J Orthod Dentofac Orthop. 2004;125(3):294-301. https://doi.org/10.1016/j.ajodo. 2003.04.016.

4. Giancotti A, Maselli A, Mampieri G, Spanò E. Pseudo-Class III malocclusion treatment with Balters' Bionator. J Orthod. 2003:30(3):203-15. https://doi. org/10.1093/ortho/30.3.203.

5. Falck F, Zimmermann-Menzel K. Kephalometrische Veränderungen bei der Behandlung von Klasse III mit dem Fränkel-Gerät. J Orofac Orthop. 2008:69(2):99-109. https://doi.org/10.1007/s00056-008-0716-7.

6. Kilic N, Celikoglu M, Oktay H. Effects of the functional regulator III on transversal changes: a postero-anterior cephalometric and model study. Eur J Orthod. 2011;33(6):727-31. https://doi.org/10.1093/ejo/cjq140.

7. Yang $Y$, Yang $K$, Zhao Y. Three-dimensional changes in the upper airway of skeletal class III patients after different orthognathic surgical procedures. J Oral Maxillofac Surg. 2017;76:1-10. https://doi.org/10.1016/j.joms.2017. 06.025 .

8. Thereza-Bussolaro C, Oh HS, Lagravère M, Flores-Mir C. Pharyngeal dimensional changes in class II malocclusion treatment when using 
Forsus ${ }^{\circledR}$ or intermaxillary elastics - an exploratory study. Int Orthod. 2019;17(4):667-77. https://doi.org/10.1016/J.ORTHO.2019.08.023.

9. Shin JH, Kim MA, Park IY, Park YH. A 2-year follow-up of changes after bimaxillary surgery in patients with mandibular prognathism: 3-dimensional analysis of pharyngeal airway volume and hyoid bone position. J Oral Maxillofac Surg. 2015;73(2):340.e1-340.e9. https://doi.org/10.1016/j. joms.2014.10.009.

10. Bohlman ME, Haponik EF, Smith PL, Allen RP, Bleecker ER, Goldman SM. CT demonstration of pharyngeal narrowing in adult obstructive sleep apnea. Am J Roentgenol. 1983;140(3):543-8. https://doi.org/10.2214/ajr. 140.3.543.

11. Ortiz MH, Brodie AG. On the growth of the human head from birth to the third month of life. Anat Rec. 1949;103(3):311-33. https://doi.org/10. 1002/ar.1091030302.

12. Ke W. A roentgenographic study of pharyngeal growth. Angle Orthod. 1952;22(1):23-7.

13. Bergland O. The bony nasopharynx. A roentgen-craniometric study. Acta Odontol Scand. 1963;21(21):35.

14. Oktay H, Ulukaya E. Maxillary protraction appliance effect on the size of the upper airway passage. Angle Orthod. 2008;78(2):209-14. https://doi. org/10.2319/122806-535.1.

15. Kilinç AS, Arslan SG, Kama JD, Özer T, Dari O. Effects on the sagittal pharyngeal dimensions of protraction and rapid palatal expansion in Class III malocclusion subjects. Eur J Orthod. 2008;30(1):61-6. https://doi.org/10. 1093/ejo/cjm076.

16. Perry JL. Anatomy and physiology of the velopharyngeal mechanism.

17. Report P. Postnatal descent of the epiglottis in man preliminary report. Arch Otolaryngol. 2015;103:06510.

18. Vorperian HK, Wang S, Schimek EM, Durtschi RB, Kent RD. Anatomic development of the oral and pharyngeal portions of the vocal tract : an imaging study a. J Acoust Soc Am. 2009. https://doi.org/10.1121/1.30755 89.

19. Sharrard W, Merrill R, Shurtleff D. Prosthetics, pathology, pediatrics, of Orthopedic Surgeons Department of Reproductive some histological parameters. 2015.

20. Handelman CS, Osborne G. Growth of the nasopharynx and adenoid development from one to eighteen years. Angle Orthod. 1976;46(3):24359. https://doi.org/10.1043/0003-3219(1976)0462.0.CO;2.

21. Tourné LPM. Growth of the pharynx and its physiologic implications. Am J Orthod Dentofac Orthop. 1991;99(2):129-39. https://doi.org/10.1016/ 0889-5406(91)70115-D.

22. Ronen O, Malhotra A, Pillar G. Influence of gender and age on upperairway length during development. Pediatrics. 2007;120(4):e1028-34. https://doi.org/10.1542/peds.2006-3433.

23. Park SB, Kim YI, Son WS, Hwang DS, Cho BH. Cone-beam computed tomography evaluation of short- and long-term airway change and stability after orthognathic surgery in patients with Class III skeletal deformities: bimaxillary surgery and mandibular setback surgery. Int J Oral Maxillofac Surg. 2012;41(1):87-93. https://doi.org/10.1016/j.ijom. 2011.09.008.

24. Lieberman DE, McCarthy RC, Hiiemae KM, Palmer JB. Ontogeny of postnatal hyoid and larynx descent in humans. Arch Oral Biol. 2001;46(2):11728. https://doi.org/10.1016/S0003-9969(00)00108-4.

25. Cervino G, Fiorillo L, Arzukanyan AV, Spagnuolo G, Cicci M. Dental restorative digital workflow: digital smile design from aesthetic to function. Dent J. 2019. https://doi.org/10.3390/dj7020030.

26. Mah JK, Huang JC, Choo H. Practical applications of cone Beam computed tomography in orthodontics. J Am Dent Assoc. 2010;141(3):7s-13s. https://doi.org/10.1136/bmj.c4875.7.

27. Crimi S, Defila ÃL, Nanni M, et al. Three-dimensional evaluation on cortical bone during orthodontic surgical treatment. J Craniofac Surg. 2020;31(6):1637-46. https://doi.org/10.1097/SCS.00000000000006592.

28. Lorenzoni DC, Bolognese AM, Garib DG, Guedes FR, Sant'Anna EF. Conebeam computed tomography and radiographs in dentistry: aspects related to radiation dose. Int J Dent. 2012. https://doi.org/10.1155/2012/ 813768.

\section{Publisher's Note}

Springer Nature remains neutral with regard to jurisdictional claims in published maps and institutional affiliations.
Ready to submit your research? Choose BMC and benefit from:

- fast, convenient online submission

- thorough peer review by experienced researchers in your field

- rapid publication on acceptance

- support for research data, including large and complex data types

- gold Open Access which fosters wider collaboration and increased citations

- maximum visibility for your research: over $100 \mathrm{M}$ website views per year

At BMC, research is always in progress.

Learn more biomedcentral.com/submissions 